\title{
General Strategy for Designing Core-Shell Nanostructured Materials for High-Power Lithium Ion Batteries
}

\author{
Laifa Shen, ${ }^{\dagger, \ddagger}$ Hongsen $\mathrm{Li}^{\dagger}{ }^{\dagger}$ Evan Uchaker, ${ }^{\ddagger}$ Xiaogang Zhang, ${ }^{* \dagger}$ and Guozhong Cao ${ }^{* \dagger}$ \\ ${ }^{\dagger}$ College of Material Science \& Engineering, Nanjing University of Aeronautics and Astronautics, Nanjing, 210016, People’s Republic \\ of China \\ ${ }^{\ddagger}$ Department of Materials Science and Engineering, University of Washington, Seattle, Washington, 98195, United States
}

\author{
Supporting Information
}

ABSTRACT: Because of its extreme safety and outstanding cycle life, $\mathrm{Li}_{4} \mathrm{Ti}_{5} \mathrm{O}_{12}$ has been regarded as one of the most promising anode materials for next-generation high-power lithium-ion batteries. Nevertheless, $\mathrm{Li}_{4} \mathrm{Ti}_{5} \mathrm{O}_{12}$ suffers from poor electronic conductivity. Here, we develop a novel strategy for the fabrication of $\mathrm{Li}_{4} \mathrm{Ti}_{5} \mathrm{O}_{12} /$ carbon core-shell electrodes using metal oxyacetyl acetonate as titania and single-source carbon. Importantly, this novel approach is simple and general, with which we have successfully produce nanosized particles of an olivine-type $\mathrm{LiMPO}_{4}(\mathrm{M}=\mathrm{Fe}, \mathrm{Mn}$, and $\mathrm{Co})$ core with a uniform carbon shell, one of the leading cathode materials for lithium-ion batteries. Metal acetylacetonates first decompose with carbon coating the particles, which is followed by a solid state reaction in the limited reaction area inside the carbon shell to produce the LTO/C $\left(\mathrm{LMPO}_{4} / \mathrm{C}\right)$ core-shell nanostructure. The optimum design of the core-shell nanostructures permits fast kinetics for both transported $\mathrm{Li}^{+}$ions and electrons,

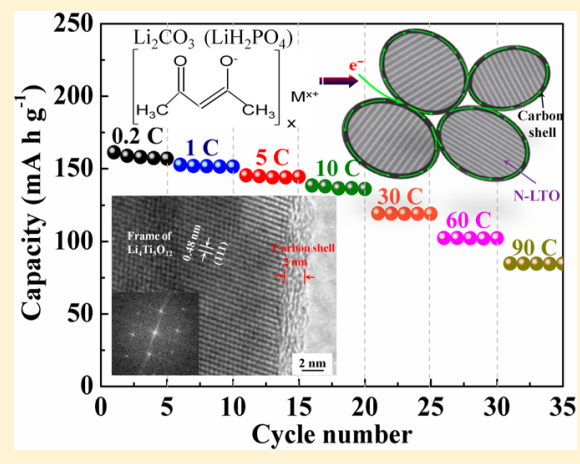
enabling high-power performance.

KEYWORDS: Lithium ion batteries, $\mathrm{Li}_{4} \mathrm{Ti}_{5} \mathrm{O}_{12}$, lithium metal phosphates, core-shell structures, anode, cathode

\begin{abstract}
T ithium-ion batteries (LIBs), dominating the portable 1 power market, have attracted enormous attention in the last several years for large-scale battery applications, such as electric vehicles (EV) and hybrid electric vehicles (HEV). ${ }^{1,2}$ However, further improvements in terms of power densities, safety, and lifetime require new materials or new structures with a higher storage capacity and faster charge and discharge rate and desired potentials. ${ }^{3-6}$ Graphitic carbon is commonly used as an anode in commercial LIBs but exhibits poor rate performance due to its low Li diffusion coefficient and presents serious safety issues because of potential solid electrolyte interphase (SEI) film formation. ${ }^{7-10}$ As for cathode materials, lithium transition metal oxides suffer from the intrinsic disadvantage of poor thermal stability due to the release of oxygen from the highly delithiated oxide materials. ${ }^{11}$ Advanced materials with better safety and excellent rate capability are critical components for the next generation of LIBs.

Compared to graphite, spinel $\mathrm{Li}_{4} \mathrm{Ti}_{5} \mathrm{O}_{12}$ (LTO) exhibits a relatively high lithium insertion/extraction voltage of approximately $1.55 \mathrm{~V}$ ( vs $\mathrm{Li} / \mathrm{Li}^{+}$), which circumvents the formation of the SEI and suppress lithium dendrite deposition on the surface of the anode. ${ }^{12-14}$ As a zero-strain insertion material, LTO possesses excellent reversibility and excellent Li-ion mobility in the charge-discharge process. ${ }^{15-17}$ As a cathode material, olivine-type $\mathrm{LiMPO}_{4}(\mathrm{M}=\mathrm{Fe}, \mathrm{Mn}, \mathrm{Co}$, and $\mathrm{Ni})$ compounds which display high Li-ion mobility, superior safety properties, and high electrochemical and thermal stability. ${ }^{18-23}$ Therefore, a $\mathrm{LiMPO}_{4} / \mathrm{LTO}$ cell system possessing unique properties
\end{abstract}

would enable a promising rechargeable batteries for large-scale application.

However, both materials suffer from poor electronic conductivity (for example: $S_{\mathrm{LTO}}<10^{-13} \mathrm{~S} \mathrm{~cm}^{-1}$ and $S_{\mathrm{LiMnPO}_{4}}$ $<10^{-10} \mathrm{~S} \mathrm{~cm}^{-1}$ ), making it a challenge to achieve high capacity at high rates. ${ }^{24-27}$ Several efforts have already been completed in an attempt to address this problem by tailoring the particle size of the electroactive materials to reduce both the ionic and electronic transportation distance ${ }^{28-30}$ and enhance the electronic conductivity with surface conductive coatings. ${ }^{31-34}$ Due to its unique chemical and physical properties, carbon coating is the most effective way to enhance the conductivity while protecting the electrode from direct contact with the electrolyte, resulting in an enhanced cycle life of the battery. ${ }^{35}$ Coatings are usually formed by mixing a carbon precursor with the preferred active materials prior to heat treatment at high temperature in an inert or reducing atmosphere. For example, Jung and co-workers reported on a carbon-coated LTO microsphere via solid-state reaction using a mixture of $\mathrm{TiO}_{2}$, $\mathrm{Li}_{2} \mathrm{CO}_{3}$, and pitch. ${ }^{36}$ It is difficult to form a uniform carbon layer on the surface of active particles while suppressing undesired particle growth during the annealing stage due to the dissimilarity between the carbon additive and the metal

Received: August 1, 2012

Revised: October 19, 2012

Published: October 23, 2012 
Scheme 1. (a) Schematic Diagram of the Conventional Solid-State Process for Micrometer-Sized Electroactive Materials and the New Strategy for the Fabrication of Nano-Sized Electroactive Materials with the Core-Shell Structure. (b) Electron-Transfer Pathway
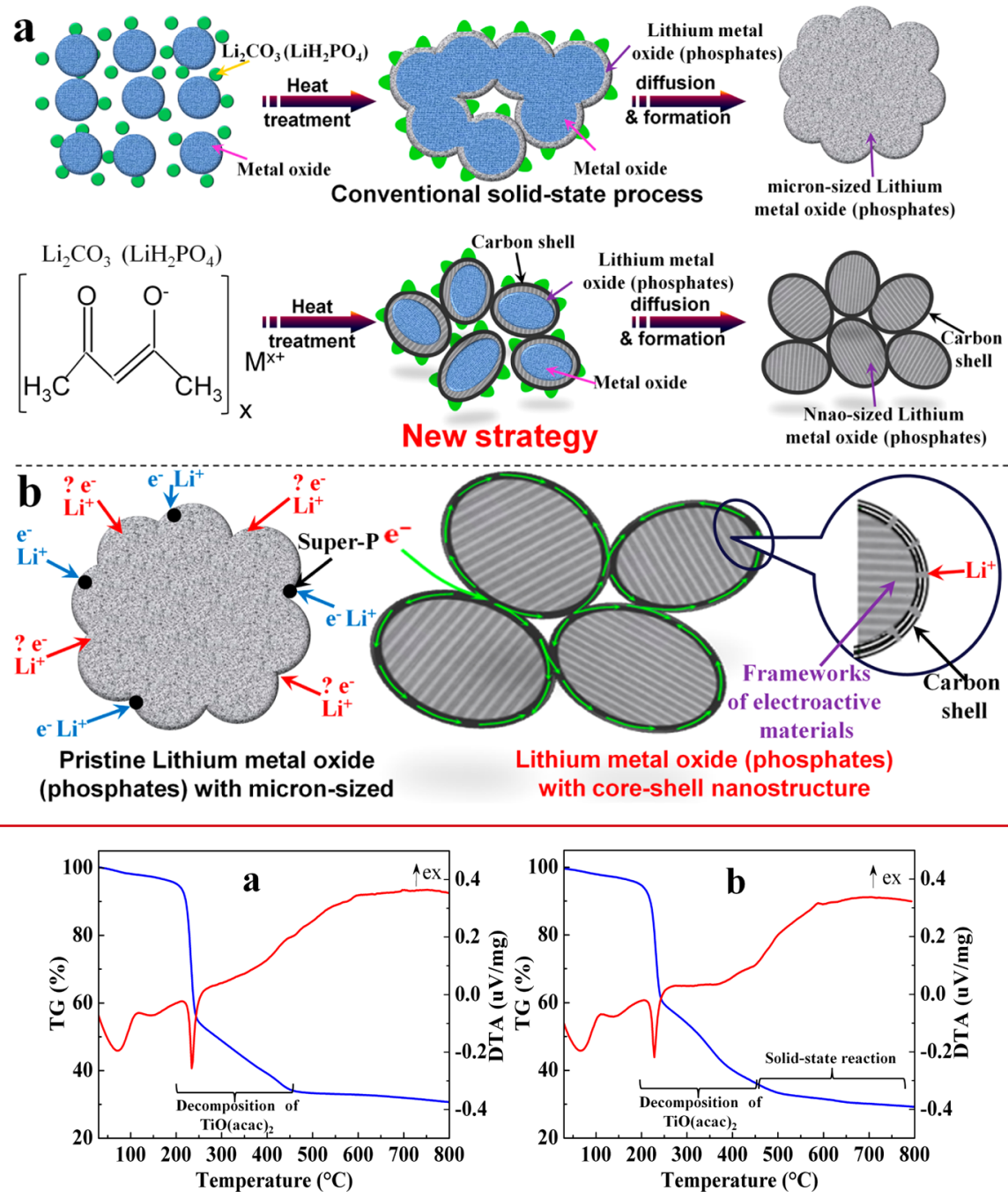

Figure 1. TG-DTA curves of (a) $\mathrm{TiO}(\mathrm{acac})_{2}$ and (b) the mixed $\mathrm{TiO}(\mathrm{acac})_{2}$ and $\mathrm{Li}_{2} \mathrm{CO}_{3}$.

precursor. So this method presents a very limited improvement on the electrochemical performance.

Here, we report a novel yet generally applicable strategy for the fabrication of optimum nanostructured materials by a simple solid-state reaction without the addition of external carbon sources. The unique electrode architectures formed a perfect electroactive nanocore coated with a uniform carbon shell with a thickness of approximately $1-2 \mathrm{~nm}$ that exhibits superior rate capability and excellent cycling stability for highpower LIBs.

Scheme 1 illustrates fabrication processes and resulting architectures of the materials by the process developed in this work and the conventional approach. Unlike conventional solid-state processes where only micrometer-sized electroactive materials are obtained, our new strategy for fabrication of nanosized electroactive materials with the core-shell structure is briefly described in Scheme 1a. For the fabrication of nanosized $\mathrm{Li}_{4} \mathrm{Ti}_{5} \mathrm{O}_{12} /$ carbon (N-LTO/C), $\mathrm{TiO}(\mathrm{acac})_{2}$ was used as the titania and single-source carbon and mixed with the lithium salt $\mathrm{Li}_{2} \mathrm{CO}_{3}$. The precursor was then treated by solid-state reaction. The $\mathrm{TiO}(\mathrm{acac})_{2}$ decompose first to produce a $\mathrm{TiO}_{2}$ core embedded in a carbon shell. With increasing the calcination temperature, the molten $\mathrm{Li}_{2} \mathrm{O}$ diffuses through the defects within the carbon layer to react with the $\mathrm{TiO}_{2}$ core in the limited reaction area inside the carbon layer. As the carbon and titanium dioxide are derived from the singlecomponent precursor, undesired particle growth is effectively suppressed during annealing in the present synthesis, resulting in smaller nanocrystalline LTO particles with a complete and uniform carbon shell. The optimal core-shell nanostructure ensures the effective ambipolar diffusion of $\mathrm{Li}^{+}$and $\mathrm{e}^{-}$into and out of the LTO nanocrystalline structure (Scheme $1 \mathrm{~b}$, right) regardless of the electrical conductivity. Microsized $\mathrm{Li}_{4} \mathrm{Ti}_{5} \mathrm{O}_{12}$ (M-LTO) prepared by a conventional approach is typically only covered with a partial coating of carbon (Supporting Information, Figure S1). The effective reaction area is limited as electrons cannot reach all the positions where lithium ion insertion takes place, thus resulting in poor rate performance (Scheme 1b, left). For fabrication of olivine-type $\mathrm{LiMPO}_{4} / \mathrm{C}$ composites with the core-shell structure, the corresponding $\mathrm{MO}(\mathrm{acac})_{x}$ reacted with the proper ratio of the $\mathrm{LiH}_{2} \mathrm{PO}_{4}$ 


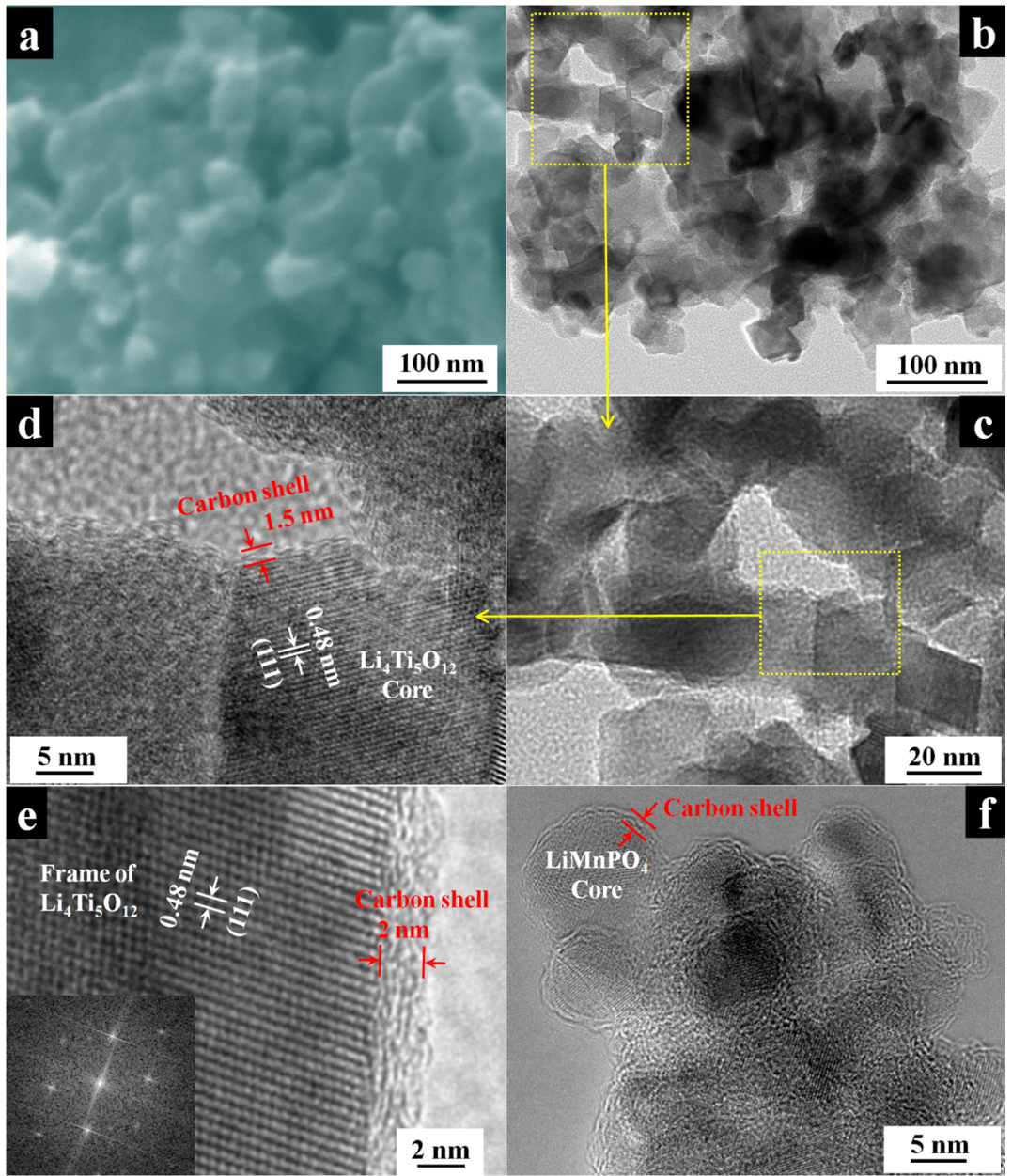

Figure 2. Typical (a) SEM and (b-e) TEM images of the N-LTO/C core-shell nanocomposite. (f) TEM image of the $\mathrm{LiMnPO}_{4} / \mathrm{C}$ core-shell nanocomposite.

component during the annealing process in an inert atmosphere.

Thermogravimetric and differential thermal analysis (TGDTA) of the thermally cured start materials was carried out under a nitrogen atmosphere to investigate the mechanism of the reaction of $\mathrm{TiO}(\mathrm{acac})_{2}$ with $\mathrm{Li}_{2} \mathrm{CO}_{3}$ (see Figure 1). For the $\mathrm{TiO}(\mathrm{acac})_{2}$ sample, weight loss clearly overlapped with a endothermic peak in the DTA trace between 200 and $450{ }^{\circ} \mathrm{C}$ and is attributed to the decomposition of $\mathrm{TiO}(\mathrm{acac})_{2}$ that results in the $\mathrm{TiO}_{2} / \mathrm{C}$ core-shell nanostructure. Above $450{ }^{\circ} \mathrm{C}$, there is hardly any weight loss, indicating that the decomposition process can be achieved below $450{ }^{\circ} \mathrm{C}$. It is also known that the crystallization of $\mathrm{TiO}_{2}$ is faster than that of carbon; thus, $\mathrm{TiO}_{2}$ crystallized before carbon, giving rise to the $\mathrm{TiO}_{2} / \mathrm{C}$ core-shell nanostructures (Supporting Information, Figure S2). ${ }^{37}$ The TG-DTA curves of the precursor mixture are similar with $\mathrm{TiO}(\mathrm{acac})_{2}$ below $450{ }^{\circ} \mathrm{C}$, indicating that a similar decomposition process occurs. However, the weight loss can still be observed at $450-750{ }^{\circ} \mathrm{C}$ and can be attributed to gas release during the solid state reaction between $\mathrm{TiO}_{2}$ and $\mathrm{LiCO}_{3}$. When heat-treating the starting materials, $\mathrm{TiO}(\mathrm{acac})_{2}$ first decompose with a carbon coating on the exterior of $\mathrm{TiO}_{2}$, which is followed by a solid state reaction in the limited reaction area inside the carbon shell to produce the LTO/C core-shell nanocomposite.
Figure $2 \mathrm{a}$ is the SEM image of the N-LTO/C composite, which consists of irregular aggregated nanoparticles. The TEM images shown in Figure $2 \mathrm{~b}$ and $\mathrm{c}$ reveal that the product is composed of LTO nanoparticles of $20-50 \mathrm{~nm}$ in diameter. A high-magnification TEM image (Figure 2d,e) reveals that a thin carbon shell (approximately 1-2 nm thick) has formed from the carbonization of organic macromolecular residues that coated every crystallite to form a LTO/C core-shell structure. The carbon content of the prepared N-LTO/C composite is measured using thermogravimetric analysis and made up $\sim 11$ wt \% of the specimen (Supporting Information, Figure S3). The Brunauer-Emmett-Teller (BET) surface area of N-LTO/ C composite is $79 \mathrm{~m}^{2} \mathrm{~g}^{-1}$ (Supporting Information, Figure S4), which are almost double higher than the calculated surface area (Supporting Information, Figure S5). The excessive specific area may be attributed to the porous carbon shell, core materials, or core-shell agglomerates. $\mathrm{Li}^{+}$can easily pass through the thin carbon shell for the insertion reaction with LTO which is accompanied by the accepted electrons. Moreover, LTO crystallites are connected to each other through the carbon shell, thereby ensuring electrical continuity around the crystallites.

This method is also used to fabricate nanosized $\mathrm{LiMPO}_{4} / \mathrm{C}$ composites with the core-shell structure. After decomposition of the $\mathrm{FeO}(\mathrm{acac})_{3}$ and solid state reaction with $\mathrm{LiH}_{2} \mathrm{PO}_{4}$, a $\mathrm{LiFePO}_{4} / \mathrm{C}$ composite comprised of a nanosized $\mathrm{LiFePO}_{4}$ core 
(10-40 nm) and a uniform carbon shell (1-2 nm) was obtained (Supporting Information, Figure S6). In addition, $\mathrm{LiMnPO}_{4} / \mathrm{C}$ (Figure 2f, Supporting Information, Figure S7) and $\mathrm{LiCoPO}_{4} / \mathrm{C}$ (Supporting Information, Figure S8) coreshell nanostructured composites were successfully prepared using this method. It is demonstrated that this unified approach is very effectively in yielding core-shell nanostructured electroactive materials.

As seen from Figure 3, all of the diffraction peaks of the $\mathrm{N}$ LTO/C specimen could be indexed to the spinel structure form

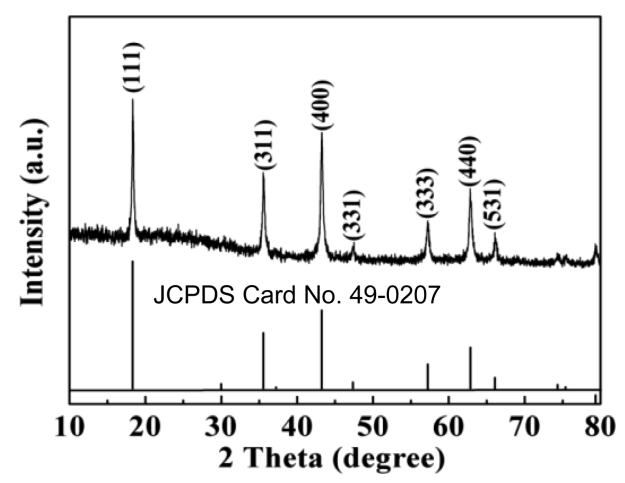

Figure 3. XRD pattern of the N-LTO/C. of LTO with the Fd3m space group (JCPDS 49-0207). The Xray diffraction (XRD) patterns of M-LTO using anatase $\mathrm{TiO}_{2}$ as the raw material are shown in Figure S9. Although the basic spinel phase was formed for the samples synthesized with anatase as the raw material and treated with the same calcination procedure $\left(750{ }^{\circ} \mathrm{C}\right.$ for $\left.6 \mathrm{~h}\right)$, a considerable amount of rutile $\mathrm{TiO}_{2}$ was also observed. Pure phase LTO was formed only after calcination at $800{ }^{\circ} \mathrm{C}$ for $10 \mathrm{~h}$. The solid-state reaction between the two solid phases is an interfacial reaction, ${ }^{38}$ as illustrated in Scheme $1 \mathrm{a}$. As the reaction temperature rises, the molten $\mathrm{Li}$ salt reacts with the $\mathrm{TiO}_{2}$ surface, forming nuclei and a surface layer of $\mathrm{Li}-\mathrm{Ti}-\mathrm{O}$. Meanwhile, the small anatase particles agglomerate and transform into large rutile $\mathrm{TiO}_{2}$ particles, which require longer time for lithium diffusion and higher temperature to accelerate the reaction for the subsequent solid-phase reaction. The undesired $\mathrm{TiO}_{2}$ particle growth is effectively suppressed by the in situ formation of the carbon shell derived from the singlecomponent precursor, resulting in a short diffusion distance for the molten $\mathrm{Li}_{2} \mathrm{O}$ to react with the titanium in the confined reaction area inside the carbon layer.

The optimum design of the N-LTO/C core-shell nanostructured electrode is expected to provide outstanding electrochemical performance in lithium ion cells. Figure $4 \mathrm{a}$ shows the discharge profiles of the N-LTO/C core-shell
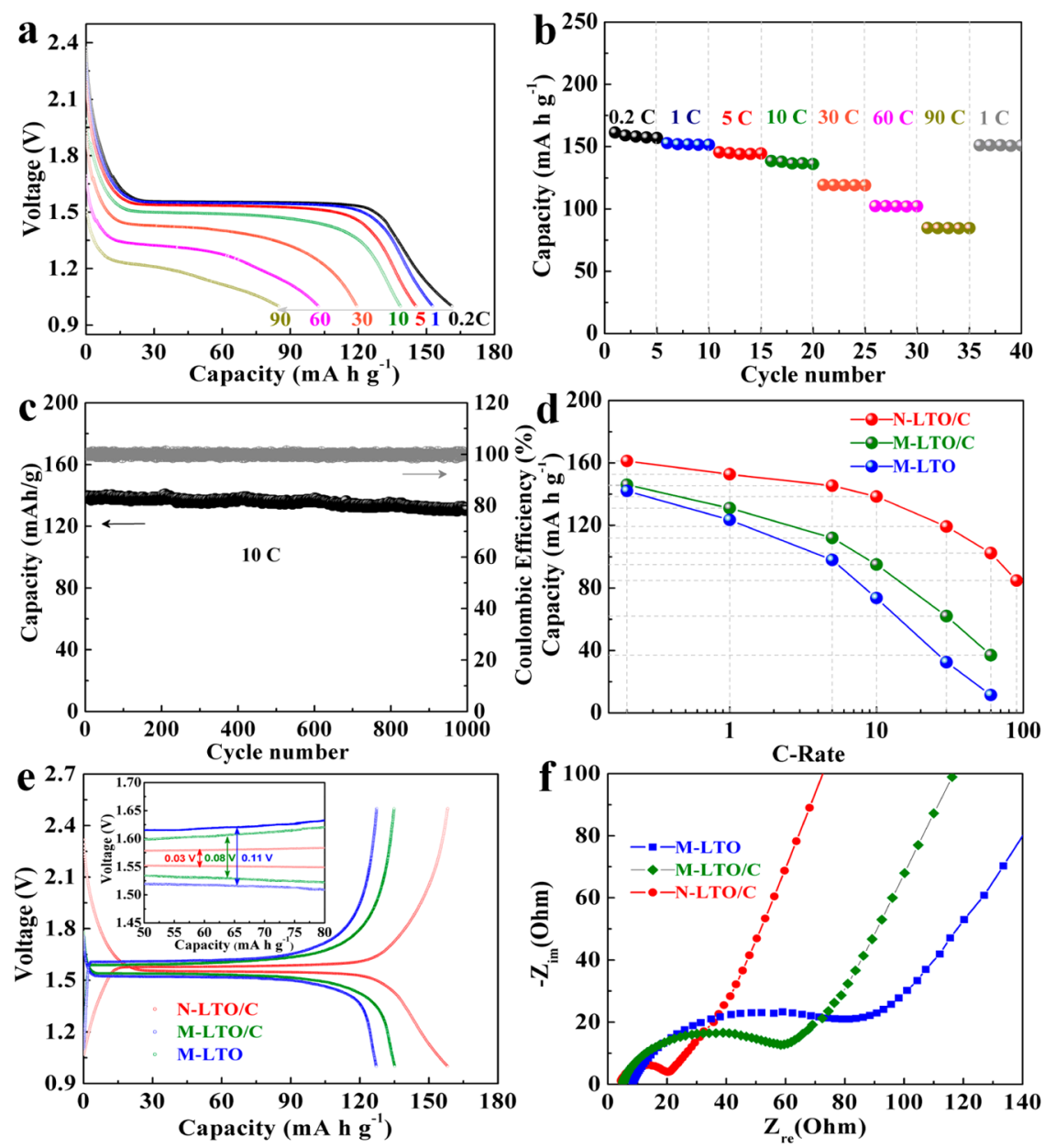

Figure 4. Electrochemical properties of the prepared N-LTO/C composite: (a) The discharge curves at different current rate. (b) The rate and cycling performances of N-LTO/C at different current rate. (c) Specific capacity and Coulombic efficiency for 1000 cycles at a rate of $10 \mathrm{C}$. A comparison of the (d) rate capacity retention, (e) voltage profiles at $0.5 \mathrm{C}$, and (f) Nyquist plots of N-LTO/C, M-LTO/C, and M-LTO. 
nanostructured electrode at the current rates of 0.2-90 C over a potential window of $1.0-2.5 \mathrm{~V}$. At the initial lower rate of 0.2 $\mathrm{C}\left(0.035 \mathrm{~A} \mathrm{~g} \mathrm{~g}^{-1}\right)$, the LTO/C core-shell nanostructured electrode showed a flat voltage plateau at the potential of $\sim 1.55$ $\mathrm{V}$ and exhibited a discharge capacity of $161 \mathrm{~mA} \mathrm{~h} \mathrm{~g}^{-1}$. As the current rate increased from 1 to 5,10 , and $30 \mathrm{C}$, the discharge capacity decreased slightly from 153 to 146,138 , and $119 \mathrm{~mA} \mathrm{~h}$ $\mathrm{g}^{-1}$, respectively. At the high rate of $60 \mathrm{C}\left(10.5 \mathrm{~A} \mathrm{~g}^{-1}\right)$, the delivered capacity was still $\sim 64 \%$ of the value achieved at $0.2 \mathrm{C}$, and even at ultrahigh rate of $90 \mathrm{C}\left(15.8 \mathrm{~A} \mathrm{~g}^{-1}\right)$, the cell was able to deliver substantial capacity, that is, $53 \%$ of the $0.2 \mathrm{C}$ value, indicating the excellent rate capability of the material. Figure $4 \mathrm{~b}$ shows the discharge capacities against different current rates, each sustained for 5 cycles. The stable cyclic performance was obtained for all rates. A specific capacity of $\sim 151 \mathrm{~mA} \mathrm{~h} \mathrm{~g}^{-1}$ was recovered when the current rate reduced back to $1 \mathrm{C}$ after 35 cycles at higher rates. The N-LTO/C electrode also demonstrated superior electrochemical performance under a long-term cyclic test at a high current rate of $10 \mathrm{C}$ (Figure 4c). The Coulombic efficiency remained constant at approximately $100 \%$. The cell retained $\sim 95 \%$ of its initial capacity after 1000 cycles at the high $10 \mathrm{C}$ rate. The superior cycling performance can be attributed to the structural stability of $\mathrm{Li}_{4} \mathrm{Ti}_{5} \mathrm{O}_{12}$ and the rapid ionic and electronic conduction in the electrode due to the carbon nanocoating. The electrochemical performance of N-LTO/C core-shell nanostructures is much better than that of nanostructured LTO, ${ }^{39}$ partially carbon-coated $\mathrm{LTO}^{9}$ doped $\mathrm{LTO}^{40}$ and LTO-graphene composites. $^{41}$

The rate capabilities of M-LTO/C and M-LTO were tested and compared with that of N-LTO/C (Figure 4d). N-LTO/C obviously exhibited a much higher storage capacity and much better rate capability than both M-LTO/C and M-LTO. For example, at a rate of $60 \mathrm{C}$, the capacity of N-LTO/C was nearly 4 times greater than M-LTO/C and nearly 9 times greater than M-LTO. A comparison of the voltage profiles for the various materials is shown in Figure 4e. It should be noted that the gap between charge and discharge of the N-LTO/C electrode was the narrowest when compared to that of M-LTO/C and MLTO electrodes, suggesting that the former had lowest overall resistance. This low ionic and electronic resistance collaborated well with the electrochemical impedance spectroscopy results presented in Figure 4f. The optimum design of nanosized LTO particles with a uniform carbon shell enables the fast migration of both lithium ions and electrons to reach the interior of each active particle, enhancing the full utilization of the nanoactive materials.

The fast lithium-ion intercalation/extraction of such coreshell architectures is also confirmed in the $\mathrm{LiMPO}_{4} / \mathrm{C}$ coreshell nanostructured electrode. The discharge capacity of the $\mathrm{LiFePO}_{4} / \mathrm{C}$ core-shell nanostructured electrode was $156 \mathrm{~mA} \mathrm{~h}$ $\mathrm{g}^{-1}$ at a rate of $1 \mathrm{C}$ and delivered a capacity of $\sim 118 \mathrm{~mA} \mathrm{~h} \mathrm{~g}^{-1}$ at a high rate of $20 \mathrm{C}\left(3.4 \mathrm{~A} \mathrm{~g}^{-1}\right)$, thereby indicating its highpower performance (Supporting Information, Figure S10a). The $\mathrm{LiFePO}_{4} / \mathrm{C}$ core-shell nanostructured electrode also possessed superior cyclic stability (only $\sim 8 \%$ capacity loss after 1000 cycles at a high rate of $10 \mathrm{C}$; Supporting Information, Figure S10b). The discharge capacities of the $\mathrm{LiMnPO}_{4} / \mathrm{C}$ core-shell nanostructured electrode decrease from 156 to $123 \mathrm{~mA} \mathrm{~h} \mathrm{~g}^{-1}$ with increasing discharge rates from 0.1 to $1 \mathrm{C}$ (Supporting Information, Figure S7d). At the rates of 0.1 and $1 \mathrm{C}$, the discharge capacities of the $\mathrm{LiCoPO}_{4} / \mathrm{C}$ is 145 and $117 \mathrm{~mA} \mathrm{~h} \mathrm{~g}^{-1}$, respectively (Supporting Information,
Figure S8d). The rate capabilities of $\mathrm{LiMnPO}_{4} / \mathrm{C}$ and $\mathrm{LiCoPO}_{4} / \mathrm{C}$ are significantly poorer compared with the $\mathrm{LiFePO}_{4}$, which may be explained by the difference in intrinsic material properties, such as the miscibility gap. The electrochemical properties of the $\mathrm{LiMnPO}_{4} / \mathrm{C}$ core-shell nanocomposite is better than $\mathrm{LiMnPO}_{4} / \mathrm{C}$ particles $(30 \mathrm{~nm}){ }^{42}$ nanometric $\mathrm{LiMnPO}_{4},{ }^{43} \mathrm{LiMnPO}_{4}$ nanoplate, ${ }^{44}$ and carboncoated $\mathrm{LiMnPO}_{4}{ }^{45}$ The improved electrochemical performance may be attributed to small $\mathrm{LiMnPO}_{4}$ core coated with a uniform carbon shell.

In summary, a general strategy for the fabrication of coreshell nanostructured materials through a novel solid-state process has been developed. This novel method is effective in yielding core-shell nanostructured electroactive materials with some unique advantages: (1) the in situ generated carbon directly and uniform coated on the electroactive materials without the addition of an external carbon source; (2) suppressing undesired particle growth during the annealing process; (3) easy scalability for industrial application. The optimum design of the core-shell nanostructures permits fast kinetics for both transported $\mathrm{Li}^{+}$ions and electrons, enabling high-power performance. In addition, the method reported here offers a compelling case for the replacement of the industrial standard of carbon coating materials requiring the addition of a carbon source.

\section{ASSOCIATED CONTENT}

\section{S Supporting Information}

Experimental procedures, material characterization, coin cell preparation, electrode testing, TEM images of the M-LTO and M-LTO/C, additional TGA and BET data for N-LTO/C, XRD, SEM, TEM, TG-DTA, and electrochemical data for $\mathrm{LiMPO}_{4} / \mathrm{C}(\mathrm{M}=\mathrm{Fe}, \mathrm{Mn}$, and $\mathrm{Co})$. This material is available free of charge via the Internet at http://pubs.acs.org.

\section{AUTHOR INFORMATION}

\section{Corresponding Author}

*E-mail: azhangxg@nuaa.edu.cn (X.Z.); gzcao@u.washington. edu (G.C.).

\section{Notes}

The authors declare no competing financial interest.

\section{ACKNOWLEDGMENTS}

This work was supported by the National Science Foundation of the U.S. (DMR-0605159, CMMI-1030048), National Natural Science Foundation of China (No. 21173120), and Natural Science Foundation of Jiangsu Province (BK2011030). L.S. also thanks the Jiangsu Innovation Program for Graduate Education (CXZZ11_0204) and Outstanding Doctoral Dissertation in NUAA (BCXJ11-10) for financial support and the China Scholarship Council (CSC) for providing a scholarship for Ph.D. study at the University of Washington.

\section{REFERENCES}

(1) Tarascon, J. M.; Armand, M. Nature 2001, 414, 359.

(2) Tollefson, J.; Scully, T.; Witze, A.; Morton, O. Nature 2008, 454, 818

(3) Wang, Y.; Cao, G. Z. Adv. Mater. 2008, 20, 2251.

(4) Kang, E.; Jung, Y. S.; Cavanagh, A. S.; Kim, G. H.; George, S. M.; Dillon, A. C.; Kim, J. K.; Lee, J. Adv. Funct. Mater. 2011, 21, 2430.

(5) Shen, L.; Yuan, C.; Luo, H.; Zhang, X.; Xu, K.; Zhang, F. J. Mater. Chem. 2011, 21, 761. 
(6) Park, K. S.; Benayad, A.; Kang, D. J.; Doo, S. G. J. Am. Chem. Soc. 2008, 130, 14930.

(7) Amine, K.; Belharouak, I.; Chen, Z. H.; Tran, T.; Yumoto, H.; Ota, N.; Myung, S. T.; Sun, Y. K. Adv. Mater. 2010, 22, 3052.

(8) Wang, D. H.; Choi, D.; Yang, Z. G.; Viswanathan, V. V.; Nie, Z. M.; Wang, C. M.; Song, Y. J.; Zhang, J. G.; Liu, J. Chem. Mater. 2008, 20, 3435.

(9) Wang, Y. G.; Liu, H. M.; Wang, K. X.; Eiji, H.; Wang, Y. R.; Zhou, H. S. J. Mater. Chem. 2009, 19, 6789.

(10) Prakash, A. S.; Manikandan, P.; Ramesha, K.; Sathiya, M.; Tarascon, J. M.; Shukla, A. K. Chem. Mater. 2010, 22, 2857.

(11) Sun, Y. K.; Oh, S. M.; Park, H. K.; Scrosati, B. Adv. Mater. 2011, 23, 5050 .

(12) Ohzuku, T.; Ueda, A.; Yamamoto, N. J. Electrochem. Soc. 1995, 142,1431

(13) Fong, R.; Sacken, U. V.; Dahn, J. R. J. Electrochem. Soc. 1990, 137, 2009.

(14) Shen, L.; Yuan, C.; Luo, H.; Zhang, X.; Xu, K.; Xia, Y. J. Mater. Chem. 2010, 20, 6998.

(15) Amatucci, G. G.; Badway, F.; Pasquier, A. D.; Zheng, T. J. Electrochem. Soc. 2001, 148, A930.

(16) Zaghib, K.; Armand, M.; Gauthier, M. J. Electrochem. Soc. 1998, $145,3135$.

(17) Haetge, J.; Hartmann, P.; Brezesinski, K.; Janek, J.; Brezesinski, T. Chem. Mater. 2011, 23, 4384.

(18) Padhi, A. K.; Nanjundaswamy, K. S.; Goodenough, J. B. J. Electrochem. Soc. 1997, 144, 1188.

(19) Wang, Y. G.; Wang, Y. R.; Hosono, E.; Wang, K. X.; Zhou, H. S. Angew. Chem., Int. Ed. 2008, 47, 7461.

(20) Oh, S. M.; Myung, S. T.; Park, J. B.; Scrosati, B.; Amine, K.; Sun, Y. K. Angew. Chem., Int. Ed. 2012, 51, 1853.

(21) Lepage, D.; Michot, C.; Liang, G.; Gauthier, M.; Schougaard, S. B. Angew. Chem., Int. Ed. 2011, 50, 6884.

(22) Zhu, C. B.; Yu, Y.; Gu, L.; Weichert, K.; Maier, J. Angew. Chem., Int. Ed. 2011, 50, 6278.

(23) Wang, H. L.; Yang, Y.; Liang, Y. J.; Cui, L. F.; Casalongue, H. S.; Li, Y. G.; Hong, G.; Cui, Y.; Dai, H. J. Angew. Chem., Int. Ed. 2011, 50, 7364.

(24) Chen, C. H.; Vaughey, J. T.; Jansen, A. N.; Dees, D. W.; Kahaian, A. J.; Goacher, T.; Thackeray, M. M. J. Electrochem. Soc. 2001, 148, A102.

(25) Zhu, G. N.; Liu, H. J.; Zhuang, J. H.; Wang, C. X.; Wang, Y. G.; Xia, Y. Y. Energy Environ. Sci. 2011, 4, 4016.

(26) Shen, L. F.; Uchaker, E.; Zhang, X. G.; Cao, G. Z. Adv. Mater. 2012, DOI: 10.1002/adma.201203151.

(27) Shen, L. F.; Zhang, X. G.; Uchaker, E.; Yuan, C. Z.; Cao, G. Z. Adv. Energy Mater. 2012, 2, 691.

(28) Kavan, L.; Prochazka, J.; Spitler, T. M.; Kalbac, M.; Zukalova, M. T.; Drezen, T.; Gratzel, M. J. Electrochem. Soc. 2003, 150, A1000.

(29) Borghols, W. J. H.; Wagemaker, M.; Lafont, U.; Kelder, E. M.; Mulder, F. M. J. Am. Chem. Soc. 2009, 131, 17786.

(30) Lim, J.; Choi, E.; Mathew, V.; Kim, D.; Ahn, D.; Gim, J.; Kang, S. H.; Kim, J. J. Electrochem. Soc. 2011, 158, A275.

(31) Shen, L.; Yuan, C.; Luo, H.; Zhang, X.; Chen, L.; Li, H. J. Mater. Chem. 2011, 21, 14414.

(32) Jo, M. R.; Nam, K. M.; Lee, Y.; Song, K.; Park, J. T.; Kang, Y. M. Chem. Commun. 2011, 47, 11474.

(33) Jung, H. G.; Jang, M. W.; Hassoun, J.; Sun, Y. K.; Scrosati, B. Nat. Commun. 2011, 2, 516.

(34) Zhao, L.; Hu, Y. S.; Li, H.; Wang, Z.; Chen, L. Q. Adv. Mater. 2011, 23, 1385.

(35) Li, H. Q.; Zhou, H. S. Chem. Commun. 2012, 48, 1201.

(36) Jung, H. G.; Myung, S. T.; Yoon, C. S.; Son, S. B.; Oh, K. H.; Amine, K.; Scrosati, B.; Sun, Y. K. Energy Environ. Sci. 2011, 4, 1345. (37) Shanmugam, S.; Gabashvili, A.; Jacob, D. S.; Yu, J. C.; Gedanken, A. Chem. Mater. 2006, 18, 2275.

(38) Yuan, T.; Cai, R.; Wang, K.; Ran, R.; Liu, S. M.; Shao, Z. P. Ceram. Int. 2009, 35, 1757.
(39) Tang, Y. F.; Yang, L.; Qiu, Z.; Huang, J. S. J. Mater. Chem. 2009, 19, 5980.

(40) Du, G. D.; Sharma, N.; Peterson, V. K.; Kimpton, J. A.; Jia, D. Z.; Guo, Z. P. Adv. Funct. Mater. 2011, 21, 3990.

(41) Shen, L. F.; Yuan, C. Z.; Luo, H. J.; Zhang, X. G.; Yang, S. D.; Lu, X. J. Nanoscale 2011, 3, 572.

(42) Martha, S. K.; Markovsky, B.; Grinblat, J.; Gofer, Y.; Haik, O.; Zinigrad, E.; Aurbach, D.; Drezen, T.; Wang, D.; Deghenghi, G.; Exnarb, I. J. Electrochem. Soc. 2009, 156, A541.

(43) Pivko, M.; Bele, M.; Tchernychova, E.; Logar, N. Z.; Dominko, R.; Gaberscek, M. Chem. Mater. 2012, 24, 1041.

(44) Choi, D. W.; Wang, D. H.; Bae, I. T.; Xiao, J.; Nie, Z. M.; Wang, W.; Viswanathan, V. V.; Lee, Y. J.; Zhang, J. G.; Graff, G. L.; Yang, Z. G.; Liu, J. Nano Lett. 2010, 10, 2799.

(45) Rangappa, D.; Sone, K.; Zhou, Y.; Kudob, T.; Honma, I. J. Mater. Chem. 2011, 21, 15813. 